\title{
Chronic Pain after Laparoscopic Transabdominal Preperitoneal Hernia Repair: A Randomized Comparison of Light and Extralight Titanized Polypropylene Mesh
}

\author{
Stefan Schopf • Thomas von Ahnen • \\ Martin von Ahnen · Hans Schardey
}

Published online: 20 November 2010

(c) The Author(s) 2010. This article is published with open access at Springerlink.com

\begin{abstract}
Background The aim of this prospective, randomized, single-blinded clinical trial was to compare the incidence of chronic pain after laparoscopic transabdominal preperitoneal hernia repair (TAPP) using a $35-\mathrm{g} / \mathrm{m}^{2}$ titanized polypropylene mesh and a $16-\mathrm{g} / \mathrm{m}^{2}$ titanized polypropylene mesh. The reported incidence of chronic pain in patients who underwent laparoscopic hernia repair is a serious problem. The techniques of dissection, mesh fixation, and the mesh material used have all been identified as being part of the problem. Excellent biocompatibility through a unique combination of a lightweight open porous polypropylene mesh covered with a covalent-bonded titanium layer has been claimed. The aim of this study was to find out whether the titanium surface alone or the difference in material load between the two available meshes influences clinical outcomes.

Methods Three hundred eighty patients with 466 inguinal hernias were operated on between 2002 and 2006 with the laparoscopic transabdominal preperitoneal (TAPP) technique. Mesh fixation with staples was carried out routinely. After the dissection was completed just prior to the implantation of the mesh, patients were randomized into two groups. In Group A, 250 (53.6\%) inguinal hernias were repaired with a $35-\mathrm{g} / \mathrm{m}^{2}$ titanized polypropylene mesh, and in Group B, 216 (46.4\%) inguinal hernias were repaired with a $16-\mathrm{g} / \mathrm{m}^{2}$ titanized polypropylene mesh. The primary outcome was chronic pain 3 years after surgery. The degree of pain was determined using a visual analog scale
\end{abstract}

S. Schopf $(\bowtie) \cdot$ T. von Ahnen · M. von Ahnen · H. Schardey Department of General, Visceral and Vascular Surgery, Agatharied Academic Teaching Hospital

of the Ludwig-Maximilians-University Munich,

St. Agathastr. 1, 83734 Hausham/Oberbayern, Germany

e-mail: sallerschopf@aol.com
(VAS) with a range from 0 to 10 . The secondary outcome was the rate of recurrence.

Results The postoperative period of observation was at least 3 years for every patient. In both groups, $90 \%$ of the patients could be questioned and examined clinically: in Group A (Light), 5.3\% of the patients and in Group B (Extralight), 1.5\% of the patients suffered from chronic pain. Chronic pain was significantly more common in Group A than in Group B $(p=0.037)$. There was no difference with respect to the rate of recurrence: for Group A it was $3.1 \%$ and for Group B it was $2.6 \%(p=0.724)$.

Conclusions Chronic pain is not very common in patients who have had their inguinal hernias repaired with titaniumcovered polypropylene mesh. Reducing the material load from 35 to $16 \mathrm{~g} / \mathrm{m}^{2}$ seems to further improve the biocompatibility of these meshes, thus improving the clinical outcome by reducing chronic pain to a rare event. The role of staples in causing chronic pain following inguinal hernia repair may be overestimated. There was no evidence supporting the notion that the use of the $16-\mathrm{g} / \mathrm{m}^{2}$ titanized meshes is associated with increased recurrence rates.

Keywords Hernia - Laparoscopy - TAPP · Pain ·

Titanized polypropylene mesh

\section{Introduction}

Inguinal hernia repair is one of the most commonly performed operations in the world. Every year almost 60,000 inguinal hernia repairs (IHR) using transabdominal preperitoneal (TAPP) and extraperitoneal (TEP) techniques are performed in Germany [1]. In the majority of cases postoperative recovery is without complications and return to normal activities is possible within 1 week [2]. 
However, some patients complain about postoperative pain for several weeks and some suffer from chronic groin pain for months or even for years. Chronic pain was defined as "lasting for 3 months or more" using the definition of the International Association for the Study of Pain [3]. In their meta-analysis of randomized controlled trials, McCormack et al. found the incidence of chronic pain after inguinal hernia repair using the TAPP technique to be at $13.8 \%$ [4]. In the literature, several risk factors for chronic inguinal pain are mentioned. These are young age, female gender, medial hernia, open repair technique, postoperative complications, need for operation for recurrence [5], presence of preoperative pain, neurotoxic chemotherapy, depression, neuroticism, anxiety [6, 7], and an observation period of fewer than 3 years after surgery [8]. However, the staples used for mesh fixation [9] and the alloplastic mesh itself may also be major causes for chronic postoperative pain [10].

Animal studies proved that there is a correlation between the weight, biocompatibility, and shrinkage of polypropylene meshes [10]. There have been numerous clinical reports pointing out the tendency of implanted mesh to shrink extensively and migrate and penetrate neighboring organs, have an oversized load of material, and cause an associated chronic inflammatory reaction and even carcinogenic effects [10-12]. A great effort was put into the development of meshes that have improved biocompatibility.

Since 2001 titanium-covered polypropylene meshes, referring to a new type of compound material, are available. The titanium is covalently bonded to the alloplastic surface of the mesh. There is evidence from animal experiments that the titanium-coated polypropylene meshes induce a less pronounced foreign body reaction (i.e., less shrinkage) compared with identical meshes lacking a titanium coating [13].

To improve the outcome for their patients some surgeons have begun performing inguinal hernia repair using these titanized meshes. However, it was not clear which mesh to use for which kind of hernia, and it was also not clear how the $35-\mathrm{g} / \mathrm{m}^{2}$ (Light) and the $16-\mathrm{g} / \mathrm{m}^{2}$ (Extralight) versions differed concerning the rate of recurrence or chronic pain [14].

The aim of this prospective, randomized, single-blinded clinical trial was to compare the incidence of chronic inguinal pain and the rate of recurrence after laparoscopic transabdominal preperitoneal (TAPP) hernia repair using $35-\mathrm{g} / \mathrm{m}^{2}$ (Light) and $16-\mathrm{g} / \mathrm{m}^{2}$ (Extralight) titanized polypropylene mesh.

\section{Methods}

Patients who were at least 18 years old and presented at the General Surgery Unit of Agatharied Academic Teaching
Hospital of the Ludwig-Maximilians-University of Munich with a diagnosis of an inguinal or a femoral hernia were eligible to enter the study. The hernia repair was to be a laparoscopic tension-free TAPP technique with mesh fixation using titanium staples. Patients were randomized intraoperatively to receive either a $35-\mathrm{g} / \mathrm{m}^{2}$ (TiMESHLight $^{\text {TM }}$, pfm medical ag, Cologne, Germany) or a $16-\mathrm{g} / \mathrm{m}^{2}$ (TiMESH-Extralight $^{\mathrm{TM}}$, pfm medical ag) mesh for the repair of the inguinal hernia. The protocol was approved by the Institutional Review Board of the Ludwig-Maximilians-University of Munich (Ethical Committee) and informed consent was obtained from all participants.

All patients who were class IV or class $\mathrm{V}$ as defined by the American Society of Anesthesiologists (ASA) were excluded, as were those who had contraindications for general anesthesia. Further exclusion criteria were acute intra-abdominal infection such as peritonitis, previous major abdominal procedures, or a history of ileus. Patients who were participating in another trial, younger than 18 years, and mentally immature were also excluded.

Randomization was carried out using a lottery system. Letters were prepared prior to starting the trial and stored in a box. Each letter was drawn from the box and opened by a nurse just after dissection of the inguinal region and hemorrhage control were finished. The only influence that the surgeon had was the choice of the size of the mesh to be $10 \times 15 \mathrm{~cm}$ or larger. In patients with bilateral hernias, both sides were repaired with the same type of mesh. Patients were not aware of which kind of mesh was used for the repair. During the consent process (Fig. 1) prior to entering the trial, patients were informed that two new types of titanized polypropylene meshes are available and that we wanted to find out which one is the better with respect to postoperative pain and recurrence.

All patients underwent standardized TAPP repair in the presence of a surgeon experienced in TAPP repair who either performed the procedure himself or supervised it in a teaching situation. There were 13 surgeons who performed the operations. General anesthesia was used in all cases. All patients received standardized postoperative oral pain medication consisting of diclofenac $2 \times 50 \mathrm{mg}$, novaminsulfone $4 \times 500 \mathrm{mg}$, and omeprazole $1 \times 20 \mathrm{mg}$. Four times per day pain levels were routinely controlled using the VAS ranging from 1 to 10 . If at any time levels above VAS 3 were detected, additional medication (oxycodone/ naloxone $\left[\operatorname{Targin}^{\circledR}\right.$ ] $10 \mathrm{mg}$ or piritramide [Dipidolor ${ }^{\circledR}$ ] $15 \mathrm{mg}$ ) was administered until the patient reported levels below VAS 3. All patients were given standardized postoperative instructions that did not limit their activities. They could participate in sports as usual within the first 10 days except heavy-weight body building and anything that caused high-frequency movements of the psoas muscle, e.g., mountain biking. 
Fig. 1 Design of the study

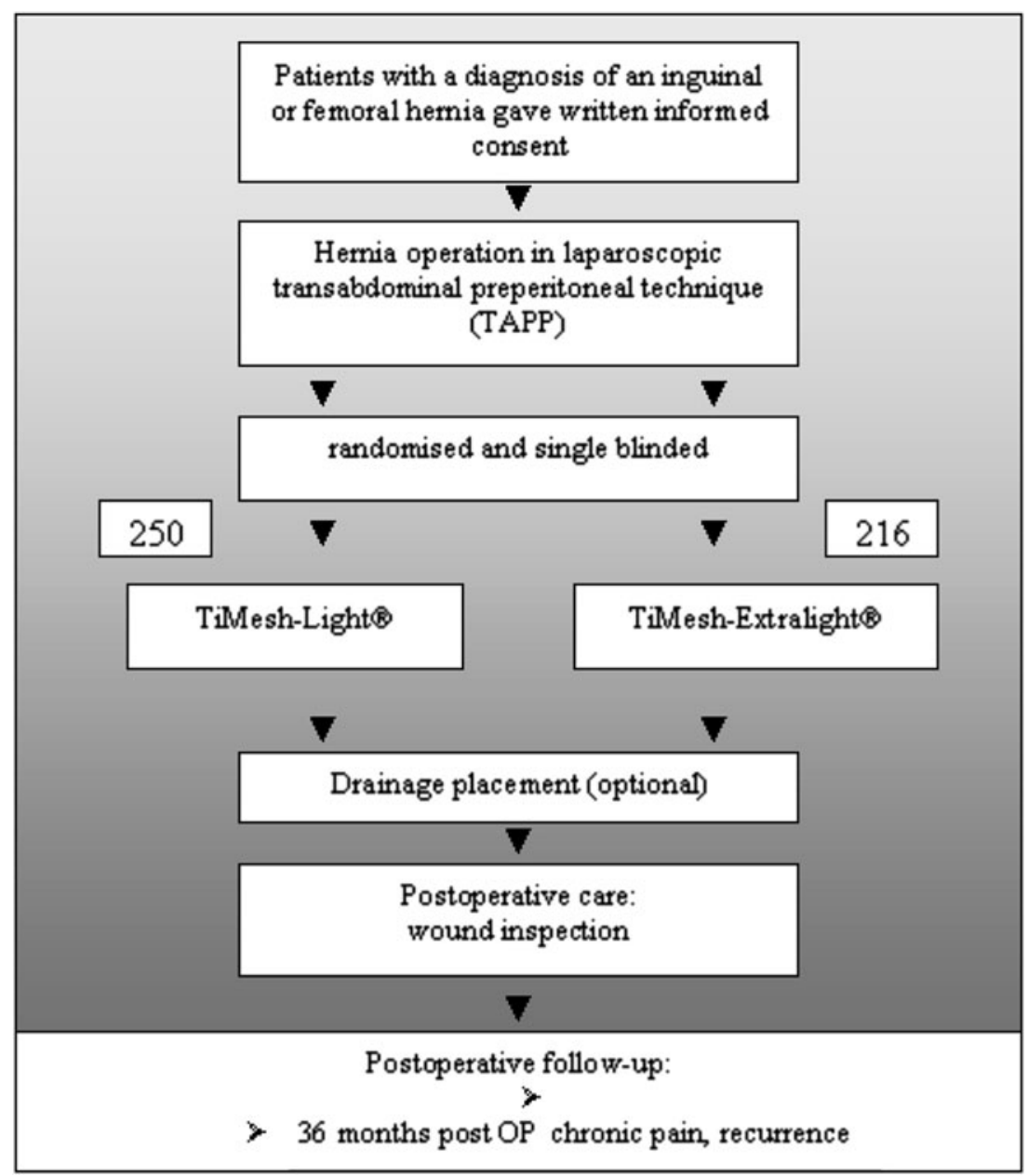

Surgical procedure

The herniotomy was carried out with the patient under general anesthesia with a single shot of prophylactic antibiotic (cefuroxime $750 \mathrm{mg}$ ). The operation was performed with the patient in the Trendelenburg position. The bladder was drained using a catheter. After pneumoperitoneum was induced, the 10-mm optic trocar was introduced at the umbilicus. Following inspection of the abdomen and the hernia, a 5-mm trocar was placed at the left lateral midclavicle. On the right lateral midclavicular line, a $12-\mathrm{mm}$ trocar was placed to insert the stapler.

From the umbilical artery medially to $4-6 \mathrm{~cm}$ past the inguinal ring laterally, the abdominal wall (peritoneum) was incised describing an arc. The epigastric vessels were identified. The medial compartment was completely dissected to the midline, exposing the rectus muscle, the horizontal pubic ramus, Hesselbach's triangle, Cooper's ligament, and the iliopubic tract. The femoral hernia orifice was exposed. The dissection went deep into the prevesical space. The peritoneum was dissected from the spermatic cord cranially to about midpsoas. In lateral hernias, the sac was completely reduced and separated from the deferent duct and testicular vessels. In direct hernias, the pseudosac was completely dissected and the hernia orifice was freed from tissue. Perihernial lipomas were excised. In all cases, titanized meshes, either TiMESH-Light or TiMESHExtralight $(15 \mathrm{~cm} \times 10 \mathrm{~cm}$ or $15 \mathrm{~cm} \times 15 \mathrm{~cm}$ mostly cut down to $15 \times 12 \mathrm{~cm}$ ) were used. Meshes were not incised.

Staple fixation of the mesh was done in the vast majority of repairs. In special cases, e.g., extremely large hernias, suture fixation was used, and in very small lateral hernias no fixation was used. Mesh was fixed with two to six titanium staples by using either an Endopath Multifire stapler (EMS, Ethicon Endo-Surgery Inc., Cincinnati, OH, USA) or an Endo-Universal stapler (Auto-Suture, Covidien, Mansfield, MA, USA). One staple each was placed at the transverse fascia at the ventral border of the mesh medially and laterally to the epigastric vessels. The other staples were optional and were placed as follows: one staple to Cooper's ligament, one to the suprapubic connective tissue in the midline, and the last staple could be variably placed, always keeping at least a 3-cm safety distance to the inguinal ligament. 
The peritoneum was closed using either staples or a running suture. In patients with bilateral hernias, the same procedure was performed on both sides. The placement of one Redon drain (Suru International, Mumbai, India) at the end of the procedure was optional. After removal of the trocars, the umbilical port site was closed at the level of the fascia. The skin was sutured. Umbilical hernias, when detected, were closed simultaneously by suture.

\section{Primary outcome}

The primary outcome of the trial was chronic inguinal pain more than 3 years after inguinal hernia repair with TAPP technique. Chronic pain was defined as pain that persisted for more than 3 months after surgery and was present at the time of follow-up examination. It included patients who regularly consumed painkillers to control inguinal pain after hernia repair at the time of follow-up examination. The postoperative follow-up period for every hernia was at least 3 years. All patients were personally questioned and examined in detail at least 3 years after surgery by the same examiner.

Measurement of pain for all patients was also performed by only one examiner who used a standardized pain protocol (Table 1). The intensity was measured with a $10-\mathrm{cm}$ VAS from 0 (no pain) to 10 (agonizing). Patients describing persistent pain were referred for further neurological, orthopedic, urological, gynecological, and psychiatric investigation (Fig. 2). When no extrainguinal cause for the pain could be found, the pain was considered to be a result of the procedure.

Patients who described postoperative pain at the time of the follow-up examination which, according to memory, subsided within 3 months after surgery did not limit their activities and returned to their prehernia lifestyles. They were documented to have suffered from acute pain. This historic perspective of the patient's postoperative period was soft data that was not considered to be a primary outcome measure.

\section{Secondary outcomes}

Secondary outcomes were early and late recurrences rates. Recurrences were confirmed by clinical examination, ultrasound, and, in some cases, laparoscopy.

\section{Statistics}

The study was designed to detect a $3 \%$ difference in chronic inguinal pain between the groups, with a sample of at least 200 hernias per group, a power of $70 \%$, and an $\alpha$ error of $5 \%$. The results were analyzed using multiple logistic regression (SPSS 15.0 for Windows and Microsoft
Table 1 Hernia follow-up: standardized pain protocol accounted for every single hernia repaired

1. Do you have any pain in relation to Pain, no pain the hernia repair?

2. How often do you have pain related Every day, once in the to the hernia repair? week, occasionally

3. How strong is the pain on a visual 0 no pain, 10 the strongest analog scale 0 to 10 ? pain

4. How much does this pain affect your No problem, a little, very daily life? limiting

5. Do you need painkillers?

Every day, once in the week, occasionally

6. What sort of painkillers do you use?

7. For how long have you been using Few days, weeks, months these painkillers?

\begin{tabular}{ll}
\hline TiMESH-Extralight & TiMESH-Light \\
$(N=194$ single & $(N=225$ single \\
hernias $)$ & hernias $)$ \\
\hline
\end{tabular}

Do you have any pain related to the hernia repair?

$\begin{array}{lll}\text { Yes } & 3 & 12\end{array}$

No $\quad 191 \quad 213$

How often do you have pain related to the hernia repair?

$\begin{array}{lll}\text { Every day } & 3 & 6 \\ \text { Once a week } & 0 & 5 \\ \text { Occasionally } & 0 & 1\end{array}$

How strong is the pain on a visual analog scale of 0 to 10 ?

$\begin{array}{lll}\text { VAS } 0 & 191 & 213 \\ \text { VAS } 1 & 0 & 1 \\ \text { VAS } 2 & 0 & 2 \\ \text { VAS } 3 & 0 & 3 \\ \text { VAS } 4 & 0 & 2 \\ \text { VAS } 5 & 0 & 2 \\ \text { VAS } 6 & 0 & 1 \\ \text { VAS } 7 & 1 & 0 \\ \text { VAS } 8 & 2 & 1 \\ \text { VAS } 9 & 0 & 0 \\ \text { VAS } 10 & 0 & 0\end{array}$

How much does this pain affect your daily life?

$\begin{array}{lll}\text { No problem } & 191 & 213 \\ \text { Little } & 0 & 6 \\ \text { Very limiting } & 3 & 6 \\ \text { Do you need painkillers? } & \\ \text { Yes } & 3 & 12 \\ \text { No } & 191 & 213\end{array}$

What sort of painkillers do you use?

$\begin{array}{lll}\text { NSAR } & 3 & 12\end{array}$

Acupuncture 220

Excel 2000). In the primary analysis, the rates of chronic inguinal pain in patients who received TiMESH-Extralight and TiMESH-Light were compared. The values are expressed as median first and third quartile, mean and 
range, or relative frequencies. A one-sided $P<0.05$ was considered significant.

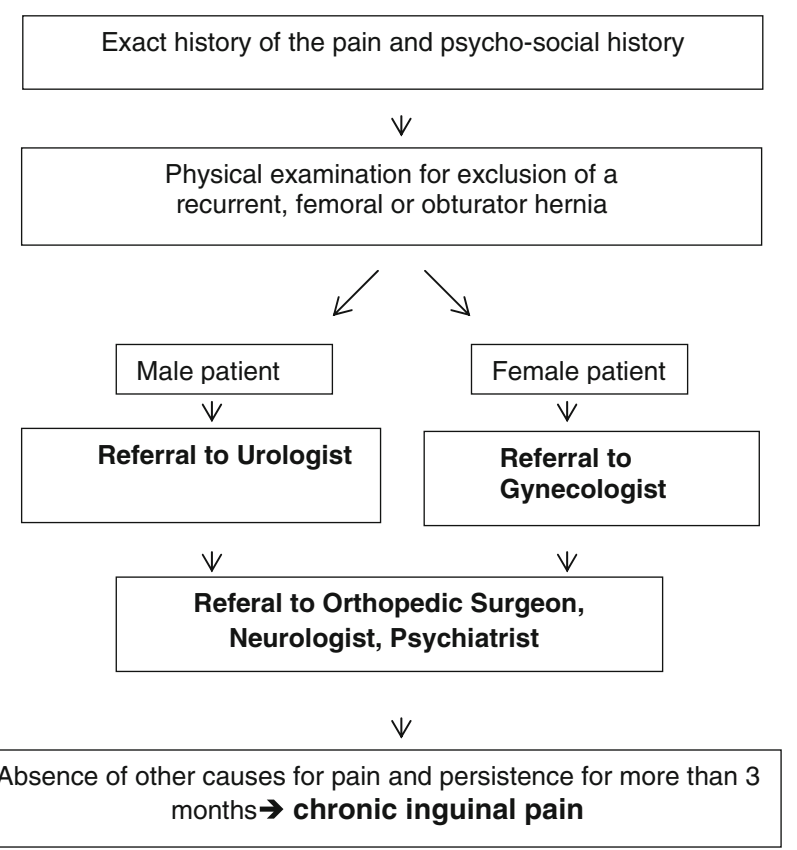

Fig. 2 Approach to patients with pain

\section{Results}

Baseline characteristics of the patients

Between October 2002 and January 2006, all 380 patients with 466 inguinal hernias underwent inguinal hernia repair with the TAPP technique. The 3-year follow-up period for the last patient ended in January 2009. Of the 380 patients operated on, 344 came personally for a physical examination and questioning in detail, for a follow-up rate of $90 \%$. The response rate was the same in both groups: $90.0 \%$ (225 of 250 hernias) for Group A (Light) and $89.8 \%$ (194 of 216 hernias) for Group B (Extralight).

Table 2 shows the baseline characteristics of the patients according to the two treatment groups. Demographic characteristics, the characteristics of hernia, and ASA classification were similar in both groups. There was no statistical difference $(P>0.05$, Table 2$)$.

Chronic pain

Postoperative pain was reported by 75 of 419 (17.9\%) investigated inguinal hernias. In 60 patients, the pain fell into the category of acute and was limited to the immediate postoperative period of 3 months or less. Acute pain was more common in Group B (Extralight), with $22.4 \%$, than in
Table 2 Baseline characteristics of the patients according to treatment group

\begin{tabular}{|c|c|c|c|c|c|}
\hline \multirow{4}{*}{$\begin{array}{l}\text { No. all patients }(n=380) \\
\text { Number of all hernias }(n=466)\end{array}$} & \multirow{2}{*}{\multicolumn{2}{|c|}{$\begin{array}{l}\text { TiMESH-Light } \\
n=206\end{array}$}} & \multicolumn{2}{|c|}{ TiMESH-Extralight } & \multirow[t]{4}{*}{$P$ value } \\
\hline & & & $n=$ & & \\
\hline & \multicolumn{2}{|c|}{$n=250$} & \multicolumn{2}{|c|}{$n=216$} & \\
\hline & $N$ & $\%$ & $N$ & $\%$ & \\
\hline Age (years) & 55.6 & & 51.3 & & \\
\hline Gender & & & & & 0.86 \\
\hline Male & 174 & 84.50 & 148 & 85 & \\
\hline Female & 32 & 15.50 & 26 & 15 & \\
\hline Side & & & & & 0.88 \\
\hline Right & 136 & 54.40 & 119 & 55.10 & \\
\hline Left & 114 & 45.60 & 97 & 44.90 & \\
\hline ASA & & & & & 0.07 \\
\hline ASA 1 & 106 & 51.50 & 109 & 62.60 & \\
\hline ASA 2 & 73 & 35.40 & 51 & 29.30 & \\
\hline ASA 3 & 27 & 13.10 & 14 & 8.10 & \\
\hline & & & & & 0.42 \\
\hline Primary hernia & 210 & 84 & 188 & 87 & \\
\hline First recurrent hernia & 36 & 14.40 & 23 & 10.60 & \\
\hline Hernia recurrent more than once & 4 & 1.60 & 5 & 2.40 & \\
\hline & & & & & 0.13 \\
\hline Emergency intervention & 11 & 5.30 & 4 & 2.30 & \\
\hline Elective surgery & 195 & 94.60 & 170 & 97.70 & \\
\hline
\end{tabular}




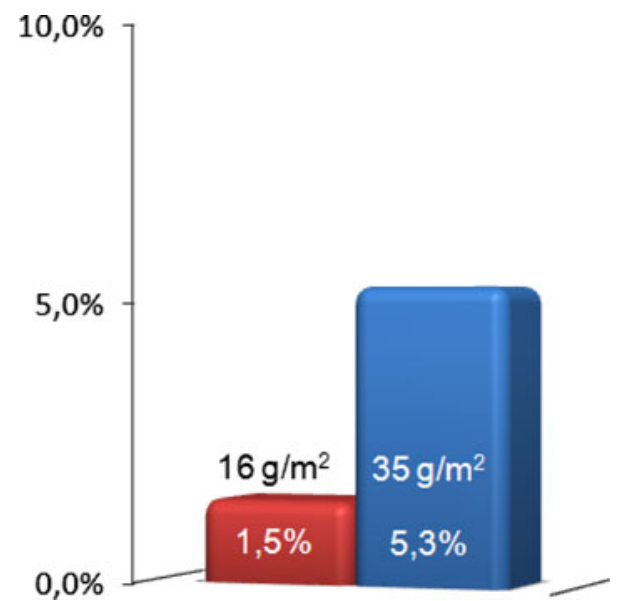

Fig. 3 Distribution of chronic pain

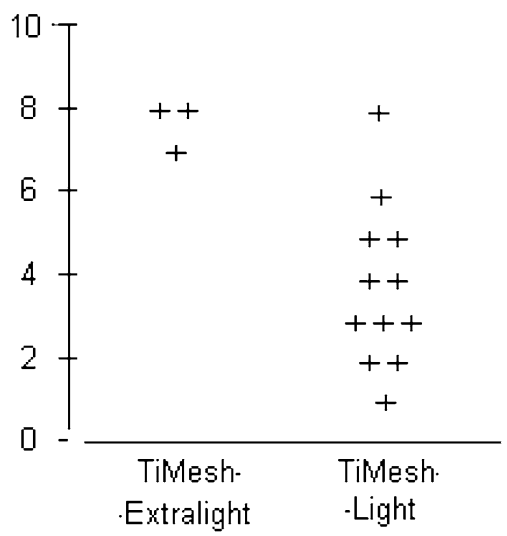

Fig. 4 Intensity of chronic pain on a visual analog scale

Group A (Light), with only 13.2\%. The difference, however, was not significant $(P>0.05)$.

In 15 inguinal hernia cases (3.6\%), patients reported chronic inguinal pain. Of these 15 inguinal hernias, 3 (1.5\%) in two patients were found in Group B (Extralight) and $12(5.3 \%)$ in Group A (Light). Chronic inguinal pain was significantly more common after implantation of TiMESH-Light mesh than after implantation of TiMESHExtralight mesh ( $P=0.037$, Fig. 3$)$. There were no intraoperative complications in any of these 15 patients with chronic pain during the postoperative course. There were no documented lesions to the spermatic cord, the nerves, or the blood vessels. One of the 15 patients with chronic inguinal pain suffered from a recurrent hernia. One patient in the TiMESH-Light group who had bilateral hernia repair had both meshes removed because the pain had been so severe. In the TiMESH-Light group, one case with chronic pain occurred after the repair of a recurrent hernia. We found no effect of the operating surgeon on the occurrence of chronic inguinal pain in the data collected.

In Group A, one inguinal hernia repair was an emergency intervention. All other 14 hernia repairs were

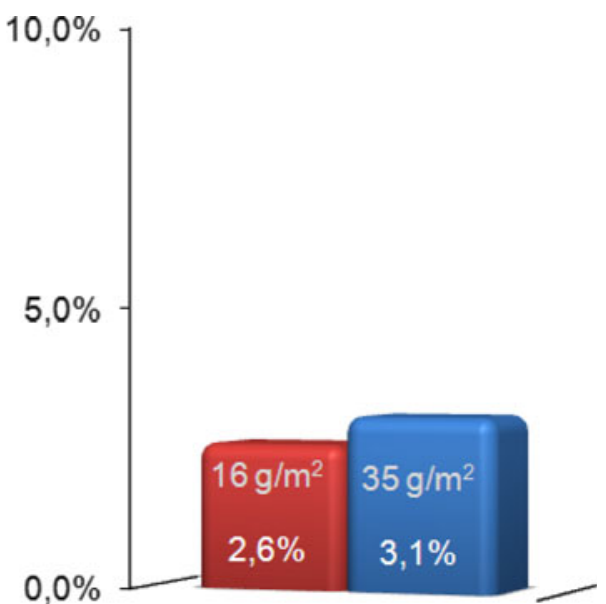

Fig. 5 Recurrence rate in both groups

performed as elective surgery. Figure 4 shows the intensity of chronic pain in the Group A (Light) and in Group B (Extralight).

\section{Recurrences}

In the 3-year observation period, 12 recurrent hernias $(2.86 \%)$ were found by postoperative investigation. Hernia recurrence was more common in Group A (Light), with seven hernias $(3.1 \%)$, than in Group B (Extralight), with five hernias $(2.6 \%)$. The difference, however, was not significant $(P=0.724$, Fig. 5). All recurrent hernias were repaired in a second operation. There were no more complications in any of the patients.

\section{Discussion}

In the past, the recurrence rate was a major outcome measure in studies dealing with inguinal hernia repair (IHR). Meanwhile, the attention has turned to other measures of success. Chronic pain has become a major focus in the last few years and there have been numerous studies dealing with pain after IHR, its type and frequency of occurrence, its risk factors, and profiles of patients predisposed to the condition. The roots of the problem are nerve injury, tissue injury, the material used for the repair, and the method of mesh fixation. Anatomical changes also might be a cause [15].

We found in our prospective, randomized, single-blinded trial that 3 years after IHR with the TAPP technique $5.3 \%$ of the patients suffered from chronic pain after the implantation of the $35-\mathrm{g} / \mathrm{m}^{2}$ titanized polypropylene mesh (TiMESH-Light). After hernia repair with the $16-\mathrm{g} / \mathrm{m}^{2}$ titanized polypropylene mesh (TiMESH-Extralight), which made up the second arm in the trial, chronic pain was 
detected in only $1.5 \%$ of the patients. This difference was significant $(P=0.037)$. The only difference between the two meshes was the material load. There was no difference in the baseline characteristics between the groups, so the reduction in chronic pain in Group B can be attributed only to the lighter-weight mesh. This is in line with the experimental results of Junge et al. [16] who very clearly demonstrated significantly improved functional consequences and morphologic tissue response with material-reduced mesh compared to a common heavy-weight polypropylene mesh. Klosterhalfen et al. [11] found in histological studies of long-term implanted meshes that the reduction of mesh material reduced the acute inflammatory reaction, caused less formation of connective tissue, and hardly maintained a chronic inflammatory process. There is much experimental evidence in the literature that material composition and mesh structure may significantly affect foreign body reaction [17]. A recent extensive review by Weyhe et al. of current randomized controlled trials and retrospective studies led to the conclusion that light meshes seem to have some advantages with respect to postoperative pain and foreign body sensation [17]. However, Light meshes offer no advantage with respect to alleviating "severe chronic groin pain." We confirmed this in our study. The only two patients in the TiMESH-Extralight group with chronic pain reported it to be quite strong. Weyhe et al. also found that the use of Light meshes was associated with an increased recurrence rate [17]. In the present study we did not find a difference between the $35-$ and the $16-\mathrm{g} / \mathrm{m}^{2}$ versions with respect to recurrence. Nonetheless, light-weight meshes have replaced their heavy-weight counterparts almost completely. This is clinical reality today, and it is independent of the fact that it may be difficult to prove why these Light meshes are favored. In our study, the lower rate of chronic pain detected in the arm with the lighter mesh confirmed expectations.

In a recent review of the literature, the incidence of chronic pain after IHR was reported to range between 25 and $30 \%$ in the majority of studies, with $2-9 \%$ reported as severe pain [18]. McCormack et al. found that the incidence of chronic pain after IHR with TAPP technique was $13.8 \%$ in a meta-analysis of randomized controlled trials [4], which was more than 5\% lower than for the examined open repairs. Aasvang and Kehlet found in their review of the present literature that inguinal herniorrhaphy may be followed by a risk of chronic pain in about $12 \%$ of patients (18\% after open and $6 \%$ after laparoscopic repair), with a clinically significant effect on daily activities [19]. Grant et al. [20] found pain and numbness to be less of a problem after laparoscopic repair than after open repair. A wellconducted, large, randomized controlled multicenter trial found a $10 \%$ incidence of chronic pain after laparoscopy and $14 \%$ after open surgery in 1983 patients $(P<0.05)$ without significant differences in VAS scores between the two groups at 6, 12, and 24 months. Kroninger [21] reported chronic pain at a rate of $15 \%$ after TAPP repair in a long-term follow up ( $>52$ months).

Several trials reported the incidence of chronic pain due to IHR after a follow-up of 1 year [4]. Our patients were followed up for 3 years after surgery, so the number of patients feeling pain may be reduced as a result of the follow-up time interval used. Courtney et al. [22] used the Wisconsin Brief Pain Questionnaire, which measures pain severity and the impact of pain on function using 0-10 rating scale, to assess the long-term outcomes in 126 patients who reported severe or very severe pain within 3 months after IHR. Of the 86 who responded after 2.5 years, $71 \%$ still reported pain, which was severe or very severe in $26 \%$ of the cases and mild or very mild in $45 \%$ of the cases. This study demonstrates that the number of patients complaining and the severity of the pain both diminish over time. However, despite some available data, there is an overall lack of well-designed prospective studies quantifying the time course of post-herniorrhaphy pain. Even in view of the evidence suggesting a "burn-out" effect of the pain complaints, we find that the very low rate detected in both of our TiMESH groups cannot be attributed only to the time factor.

The incidence of short- or long-term chronic pain after laparoscopic IHR with TAPP technique as reported in the literature is generally higher than the results of the present trial. Chronic pain in $5.3 \%$ of the patients after 3 years after IHR with TAPP technique using $35-\mathrm{g} / \mathrm{m}^{2}$ titanized polypropylene mesh (Light) offers a good result in comparison with the literature. A rate of $1.5 \%$ when $16-\mathrm{g} / \mathrm{m}^{2}$ titanized polypropylene mesh (Extralight) is used can be classified as a rare event. The data are rather solid since it is derived from a prospective randomized study with a large sample size of 466 hernias repairs and a high-quality follow-up, i.e., physical examination and personal questioning of $90 \%$ of the patients operated on. de Jonge et al. [23] stated after an extensive review of randomized trials, considered to be the "gold standard" of evidence, that the majority were using the VAS to assess pain, suggesting that there is a certain amount of standardization that can better enable interstudy comparison. Even though this particular quality standard was met by the present study, current instruments used for the evaluation of chronic pain need to be improved and prospectively validated.

The mesh used is the most probable reason for the low rate of chronic pain in this study. There are several modern concepts integrated into these prosthetic meshes, such as the light weight, pore size $\geq 1 \mathrm{~mm}$ [12], monofile fiber, and titanium surface, that may have made a clinical difference, at least in this study, when compared to other meshes used in hernia repair. The low rate of chronic pain 
detected in both groups in the present study may have to do not only with the reduced weight but also with the unique titanium surface. With respect to several histological and histochemical parameters of biocompatibility, the titanized polypropylene mesh proved advantageous compared with the other modern meshes in animal experiments. Heavyweight titanium-coated polypropylene meshes induce a less pronounced foreign body reaction than identical meshes with no titanium coating. Since the amount of material implanted is identical, this must be attributed solely to the titanium coating [13]. The favorable biocompatibility of the titanized meshes that supposedly cause less foreign body reaction and less shrinkage than other modern meshes as demonstrated in animal experiments [13, 24] may also hold true in humans.

What causes the pain in those patients still suffering after 3 years? In addition to the mesh there is surgical trauma, direct nerve injury, and the use of staples that may have also played a role here. There are numerous published reports of nerve entrapment by tacks placed during laparoscopic repair. Laparoscopic hernia repair [25] without the use of tacks has been described and it eliminates the risk of misplaced tacks [26]. In addition, it is more cost effective because staplers are expensive. Others do advise to use staples because the rate of recurrence may be reduced [27]. In the present study, staples were used in both groups to an equal extent. The rate of recurrence was the same in both groups but not the rate of chronic pain. The role of staples as a major cause of chronic inguinal pain cannot be supported by our data.

Acknowledgments This study was not sponsored or supported in 480 any way by industry.

Open Access This article is distributed under the terms of the Creative Commons Attribution Noncommercial License which permits any noncommercial use, distribution, and reproduction in any medium, provided the original author(s) and source are credited.

\section{References}

1. Mohr D, Bauer J, Döbler K, Fischer B, Woldenga C (2003) BQSQualitäsbericht 2002- Modul 12/3: Hernienoperationen. Bundesgeschäftsstelle Qualitätssicherung gGmbH, Düsseldorf

2. Hamza Y, Gabr E, Hammadi H, Khalil R (2010) Four-arm randomized trial comparing laparoscopic an open hernia repairs. Int J Surg 8(1):25-28

3. Classification of chronic pain. Descriptions of chronic pain syndromes and definitions of pain terms. Prepared by the International Association for the Study of Pain, Subcommittee on Taxonomy. Pain Suppl 3:S1-22 (1986)

4. McCormack K, Scott N, Go PM, Ross SJ, Grant A, Collaboration the EU Hernia Trialists (2003) Laparoscopic techniques versus open techniques for inguinal hernia repair. Cochrane Database Syst Rev (1). Art. no.: CD001785. doi:10.1002/14651858. CD001785

5. Callesen T, Bech k, Kehlet H (1999) Prospective study of chronic pain after hernia repair. Br J Surg 86:1528-1531
6. Perkins FM, Kehlet H (2000) Chronic pain as an outcome of surgery. A review of predictive factors. Anesthesiology 93:1123-1133

7. Macrae WA (2001) Chronic pain after surgery. Br J Anaesth 87:88-98

8. Kalliomäki ML, Meyerson J, Gunnarsson U, Gordh T, Sandblom $\mathrm{G}$ (2008) Long-term pain after inguinal hernia repair in a population-based cohort; risk factors and interference with daily activities. Eur J Pain 12(2):214-225

9. Beattie GC, Rumar S, Nixon SJ (2000) Laparoscopic total extraperitoneal hernia repair: mesh fixation is unnecessary. J Laproendosc Adv Surg 10:71-73

10. Klinge U, Klosterhalfen B (1999) Meshes within the abdominal wall. Chirurg 70:876-887

11. Klosterhalfen B, Klinge U, Hermanns B, Schumpelick V (2000) Pathology of traditional surgical nets for hernia repair after longterm implantation in humans. Chirurg 71(1):43-51

12. Klinge U, Klosterhalfen B, Birkenauer V, Junge K, Conze J, Schumpelick V (2002) Impact of polymer pore size on the interface scar formation in a rat model. J Surg Res 103: 208-214

13. Scheidbach H, Tannapfel A, Schmidt U, Lippert H, Köckerling F (2004) Influence of titanium coating on the biocompatibility of a heavyweight polypropylene mesh. An animal experimental model. Eur Surg Res. 36(5):313-317

14. Schardey HM, Schopf S, Rudert W, Knappich P, HernandezRichter T (2004) Titanisiertes Polypropylennetz: erste klinische Beobachtungen nach Implantation in TAPP Technik und Ergebnisse einer Umfrage an 22 Chirurgischen Kliniken. Zentralblatt Chirurgie 129:363-368

15. Kocijan R, Sandberg S, Chan YW, Hollinsky C (2010) Anatomical changes after inguinal hernia treatment: a reason for chronic pain and recurrent hernia? Surg Endosc 24(2):395-399

16. Junge K, Klinge U, Rosch R, Klosterhalfen B, Schumpelick V (2002) Functional and morphologic properties of a modified mesh for inguinal hernia repair. World J Surg 26:1472-1480

17. Weyhe D, Belyaev O, Müller C, Meurer K, Bauer KH, Papapostolou G, Uhl W (2007) Improving outcomes in hernia repair by the use of light meshes-a comparison of different implant constructions based on a critical appraisal of the literature. World J Surg 31(1):234-244

18. Ferzli GS, Edwards ED, Khoury GE (2007) Chronic pain after inguinal herniorrhaphy. J Am Coll Surg 205(2):333-341

19. Aasvang E, Kehlet $\mathrm{H}$ (2005) Chronic postoperative pain: the case of inguinal herniorrhaphy. Br J Anaesth 95(1):69-76

20. Grant AM, Scott NW, O'Dwyer PJ, MRC Laparoscopic Groin Hernia Trial Group (2004) Five-year follow-up of a randomized trial to assess pain and numbness after laparoscopic or open repair of groin hernia. Br J Surg 91(12):1570-1574

21. Köninger J, Redecke J, Butters M (2004) Chronic pain after hernia repair: a randomized trial comparing Shouldice, Lichtenstein and TAPP. Langenbecks Arch Surg 389(5):361-365

22. Courtney CA, Duffy K, Serpell MG, O'Dwyer PJ (2002) Outcome of patients with severe chronic pain following repair of groin hernia. Br J Surg 89(10):1310-1314

23. van Hanswijck de Jonge P, Lloyd A, Horsfall L, Tan R, O'Dwyer PJ (2008) The measurement of chronic pain and health-related quality of life following inguinal hernia repair: a review of the literature. Hernia 12(6):561-569

24. Scheidbach H, Tamme C, Tannapfel A, Lippert H, Köckerling F (2004) In vivo studies comparing the biocompatibility of various polypropylene meshes and their handling properties during endoscopic total extraperitoneal (TEP) patchplasty: an experimental study in pigs. Surg Endosc 18(2):211-220

25. Sampath P, Yeo CJ, Campbell JN (1995) Nerve injury associated with laparoscopic inguinal herniorrhaphy. Surgery 118: 829-833 
26. Ferzli GS, Frezza EE, Pecoraro AM Jr., Ahern KD (1999) Prospective randomized study of stapled versus unstapled mesh in laparoscopic preperitoneal inguinal hernia repair. J Am Coll Surg 188:461-465

27. Leibl BJ, Kraft B, Redecke JD, Schmedt CG, Ulrich M, Kraft K, Bittner R (2002) Are postoperative complaints and complications influenced by different techniques in fashioning and fixing the mesh in transperitoneal laparoscopic hernioplasty? Results of a prospective randomized trial. World J Surg 26:1481-1484 